\title{
Análisis político de la guerra angloamericana contra afganistán
}

Por: Godofredo Aguillón

\section{ANTECEDENTES POLÍTICOS DEL CONFLICTO}

$\mathrm{P}$ revia a esta reflexión sobre el conflicto en Afganistán, éste país de Asia ya ha sufrido y sigue soportando Estados Unidos, con sus secuelas de dolor y destrucción de una nación que no ha vivido en paz desde hace 20 años. Los misiles y bombas de racimo lanzadas en suclo afgano son una prucba del poderío militar norteamericano, pero de graves consecuencias para la población local. especialment: para los niños indef ensos, sobre todo si los misiles han llevado uranio empobrecido como ocurrió en la guerra del Golfo en sus 110 mil acaques aćreos contra Irak, los A-10) Warthog de Estados Unidos lanzaron 940 mil proyectiles con uranio empobrecido - y en Bosnia en 1995-1996 y en la Fedcración

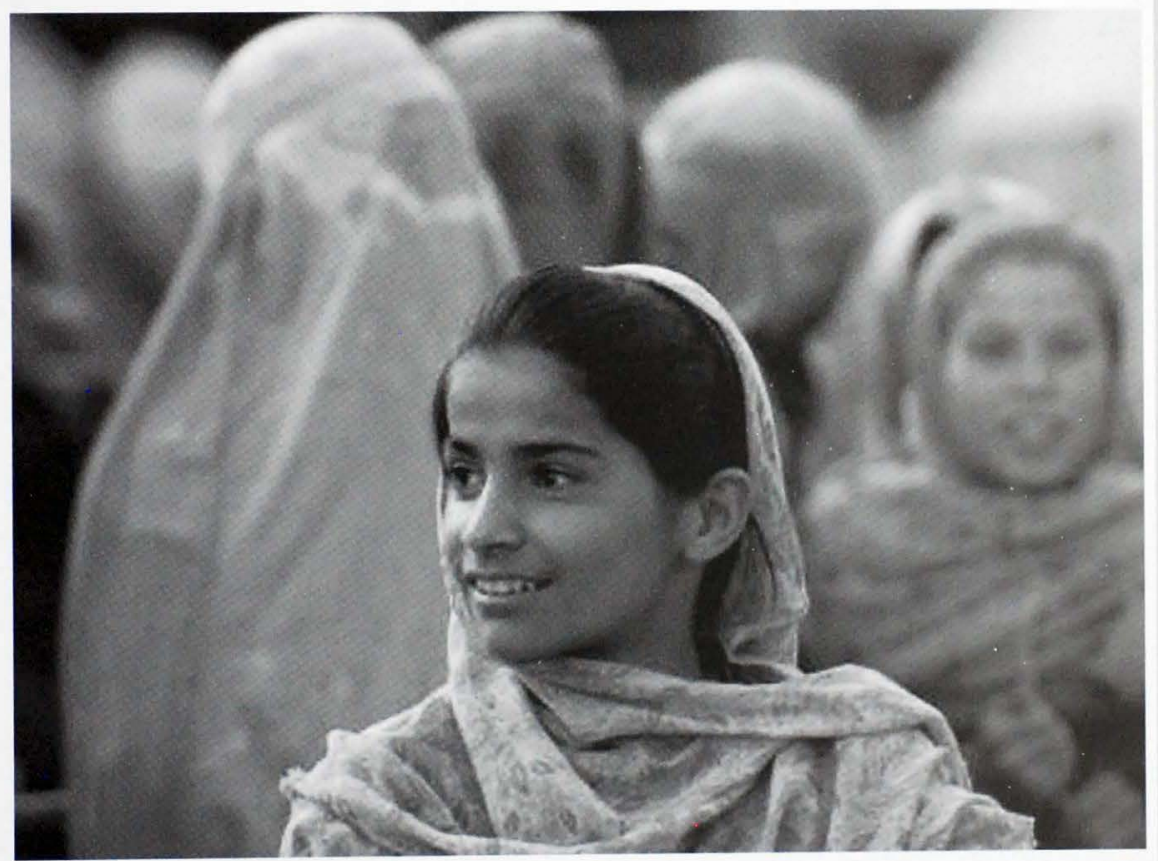


Yugoslava en $1999^{22}$ - la fuerza aérea estadounidense lanzó $30 \mathrm{mil}$ proyectiles de uranio -. El sindrome del Golfo podría reperirse hoy con la guerra contra Afganistán, con las consecuencias que esto significa para este pobre pais de Asia.

Antes de empezar la reflexión polícica sobre los atentados en territorio norteamericano a las torres gemelas y el Pentágono, es plausible plantear las siguientes interrogantes: ¿Por qué? y ¿Para qué? esos atentados en el justo corazón del orgullo americano. Qué causas, legítimas o no, indujeron a provocar semejante acto de barbarie. Con un mínimo de racionalidad sobre los acontecimientos de conmoción mundial, de cualquier naturaleza que sea, es pertinente recordar que las acciones humanas que causan dolor muchas veces son morivadas, concitadas por

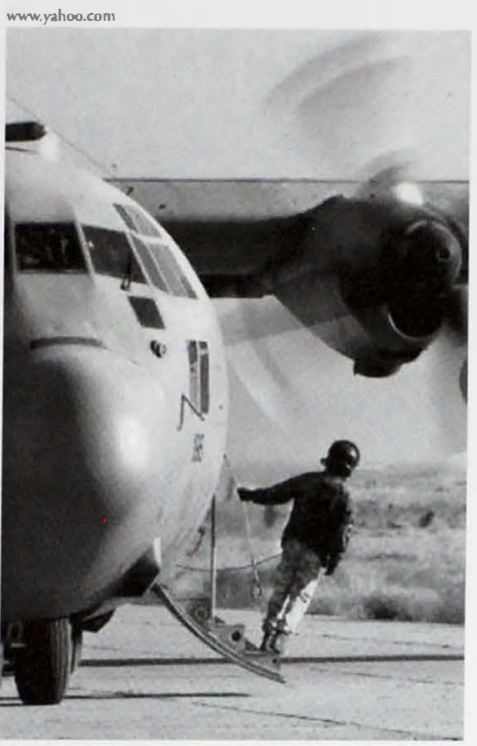
otra acción de menor o mayor grado de repercusión que la recibida, alguna razón de peso incluso injustificada- obliga al agresor a acometer una acción sin contemplación de ninguna índole.

Hay que otorgarle la razón en este punto a Hobbes en el sentido de que el hombre es el lobo del hombre. Este es el guid que sirve de contexto a la siguiente reflexión, y que suplanta al acto de condenar o juzgar si una acción es terrorista o no, sin valorar los matices y argumentos que están de fondo tras una acción de tal envergadura, y que, sin embargo, se omiten otros tipos de acciones parecidas o peores a las comeridas por grupos radicales fundamentalistas. Los análisis fuera de contexto $y$ con ensalzamiento de las pasiones enturbian una justa dimensión del origen del conflicto, amén de confundir y turbar la justa racionalidad y el pensamiento crítico. En este punto cabe advertir con el intelectual de origen paquistani Eqbal Ahmad quien vivió muchos años en Estados Unidos, que el terrorismo es un problema político, aunque hay que agregar que se refuerza utilizando otros ámbitos, uno de los cuales es la religión en el mundo árabe y musulmán.

Es necesario remarcar que cualquier tipo de terrorismo es una afrenta a la dignidad humana y son detestables como hechos abominables por sus saldos producidos, como el ocurrido el 11 de sepriembre en suelo norreamericano, pero también es cierto que alentar $y$ promover actos de terror ${ }^{33} \mathrm{en}$ muchos países no exime a Washington de responsabilidades comeridas en el pasado. Ya lo advirtió el mismo ex secretario ent 28 de Estado norteamericano, Henry Kissinger, después de los atentados del 11 de septiembre, que tan terrorista es el que mata como el que organiza y financia las operaciones delos terroristas. Hay que revisar la historia para comprender ensu justa dimensión el tema del terrorismo. Si se acepta la propuesta de Chomsky acerca de ¿Qué es terrorismo?, que ciertamente se encuentra en los manuales del ejército estadounidense, veremos lo complicado que es aplicarlo unilateralmente en la coyuntura internacional: "terror es el uso calculado de la violencia o la amenaza de violencia para lograr objetivos políticos o religiosos a través de la intimidación, la coerción o la provocación de miedo" ${ }^{24}$.

El doctor Henry Kissinger propuso el 31 de octubre ante una reunión de más de 300 personas en el London's Center for Pilicy Studies, su propia definición de terrorismo: “El terrorismo se define ataques indiscriminados contra civiles con el objetivo de romper el rejido social. ${ }^{25}$. El acto terrorista del 11 de septiembre es uno más dentro de los muchos que ha conocido la historia humana.

La historia reverbera de enconos inducidos y no inventados, al precio alto de provocar pérdidas humanas. No es lo mismo inventar una máquina sin sentimiento para una producción en serie que provocar un odio contra la maquinaria que mata y arrasa culturas sin contemplación. Uno de los aspectos mundiales que aterrorizan a la humanidad y que actúa sin misericordia es el terrorismo a escala mundial.

El discurso de Washington, en riempos de la guerta fria, para designar al enemigo (en su versión religiosa el calificativo era el representante del mal) de la humanidad para Occidente se dirigía a su otrora potencia enemiga (URSS), so pretexto de expandir por el mundo el comunismo y el socialismo, lo cual era visto como una amenaza a los intereses $y$ seguridad de ese país esparcidos por todo el mundo. Bajo esa política el gobierno norteamericano financió, organizó y dirigió varios escenarios de guerra (Nicaragua, El Salvador, Afganistán, etc.) asi como también invadió países (Panamá en 1989. Granada en 1983) que inspiraban desconfianza a la seguridad norteamericana, pero, por otra parte, toleró y alentó a gobiernos despóticos y autoritarios (gobernados por militares) 
que atentaron contra los derecho humanos de sus conciudadanos (Paraguay, Argencina, Chile, Guaremala, El Salvador, Honduras, etc).

Estas práccicas fucron una clara expresión de terrorismo de Estado para contener la línea de expansión comunista trazada por los estrategas de Washington, apuntalada precisamente en la década de los $80^{\circ}$ 's por el gobierno ultraconservador de Ronald Reagan desde la llegadaal poder en 1981. Los Documentos de Santa Fe / y /I, cuyo marco doctrinario justifica la intervención estadounidense en asuntos internos de los Estados, reforzaron la política de Washington para incervenir y apoyar incluso acciones encubiertas de la ClA. El documento Santa Fe IV reconoce explícitamente la pérdida de hegemonía de Estados Unidos en el mundo. El mismo intelectual Immanuel Wallerstein aduce que, siendo Estados Unidos una superporencia, urilizó a la CIA para expulsar o reacomodar gobicrnos que le parecían poco amistosos ${ }^{26}$.

En cl caso preciso de Afganistán, las tropas soviéticas lo invadicron en la primavera de 1979 con tanques y armamento de guerra. Se impuso un gobicrno aliado a los intereses de la URSS, obligando a los afganos opositores al régimen a librar una guerra de guerrillas para resiscir al invasor. En esta lógica de expansión soviética, Washington aprovechó la resistencia de los mujaidines, apoyándolos con armas y municiones de guerra (los famosos misiles norteamericanos Stinger dieron poder de fuego a los afganos). al ciempo que organizó, financió y adiestró a esos guerreros para derrotar a las tropas soviéticas bajo apoyos encubiertos de la $\mathrm{ClA}$, retirándose finalmente en 1989 las tropas invasoras que recibicron una estrepitosa derrota de parte de los mujaidines. Junto a esta derrota soviética, muchos de los miembros $y$ aliados del gobicrno afgano apoyados por el régimen comunista- se estima en más de $100 \mathrm{mil}$ afganos- viven hoy día en Moscú bajo la protección del gobicrno.

Hacia 1985, durance el segundo gobicrno de Ronald Reagan, éste recibió in situ a varios hombres barbudos con aspecto feroz, con curbances; fucron invitadosporsu anfitrión a la Casa Blanca para expresarles su apoyo incondicional: "Estos son el equivalente moral de los padres fundadores de Estados Unidos

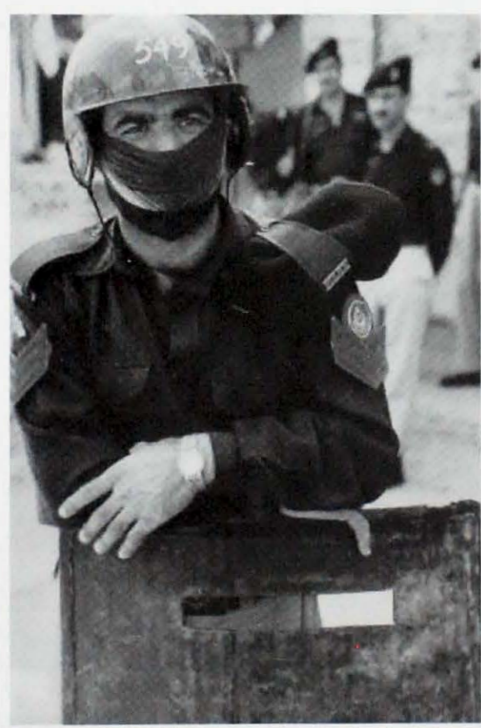

Jefferson]n ${ }^{27}$, eran precisamente los mujaidines afganos, quienes estaban en ese momento peleando contra el Imperio del Mal (URSS) en Afganistán. El resultado se saldó con una recirada-derrota de la Unión Sovićtica del suclo afgano en 1989. Los planes de la ClA más la accicud aguerrida y valience de los mujaidines en el frence de guerra se concretaron, abandonando Washington a su suerte a los victoriosos afganos con un país destruido, un error estratégico que hoy lamentan y que se les ha cornado un boomeran de desastrosas consecuencias con el régimen talibán en el poder.

De acuerdo a la compilación de Zoltan Grossman sobre intervención militar de Estados Unidos ${ }^{28}$ durante un siglo en el mundo, desde 1890 ese país arroja 133 intervenciones y acciones militares dentro y fuera del país, incluyendo diversas variantes de acciones y excluyendo ocras (movilización de la guardia nacional, ejercicios militares, estacionamiento permanente de fucrzas armadas, etc.). El académico norteamericano Noam Chomsky lo resume así: "Durante 200 años, Estados Unidos cxpulsó y exterminó a la población indígena, a millones de personas; conquistó la mitad de México; realizó depredaciones en roda la región. en el Caribe, América Central, y algunas veces más allá. Conquistó Hawai y Filipinas, y para lograrlo mató a cientos de miles de filipinos. Desde la Segunda Guerra Mundial, Estados Unidos ha extendido su alcance a todo el mundo ucilizando métodos que no precisan descripción, pero siempre matando a otros, desarrollando batallas en otros lugares. Las masacres siempre fueron en orros países, no aquí, dentro del territorio nacional"2".

Es necesario apuntar que ia acrual guerra no inició el 11 sepricmbre con los ataques a las Torres Gemelas y el Pentágono, sino que se remonta hacia 1993 con el primer ataque contra el World Trade Center, al cual le siguió, en 1995. el ataque contra cuarteles de la Guardia Nacional Árabe Saudica (SANG, por sus siglas en inglés) en Riad, y con la explosión en 1996 de las corres Khobar en las afueras de Dahran.

Posteriormente se continuó con los atentados simultáncosbombas suicidas- de las embajadas norteamericanas de Tanzania y Kenia, en octubre de 1998, ante los cuales Washington respondió, en agosto, bombardeando Afganistán - la provincia de Khost-con 75 misiles cruceros, so precexto de albergar estelugar a la agrupación 
Universidad Tecnológica de El Salvador

Análisis politico de la guerra angloamericana contra Afganistán

de AI Qaeda, a quien se le acribuyeron las responsabilidades, dejando como resultado cientos de muertos; finalmente el ataque conera el USS Cole en octubre del 2000. Estos atentados previos al II de sepriembre de 2001, ciertamente formaron parte de toda una estrategia a largo plazo para erosionar la criticada hegemonía nortearnericana. Sin embargo, Estados Unidos respondió - como acto de venganza - bélicamente, declarándoles la guerra a Afganistán y su gobierno talibán, llevándose de paso al mismo pueblo afgano que ha tenido que pagar el altísimo costo por otorgar su gobierno refugio a Osama Bin Laden, considerado por Washington como el terrorista más temible del mundo.

El conflicto, en efecto, tienc importantes dimensiones geopoliticas. De hecho, por los actores enfrentados y por los

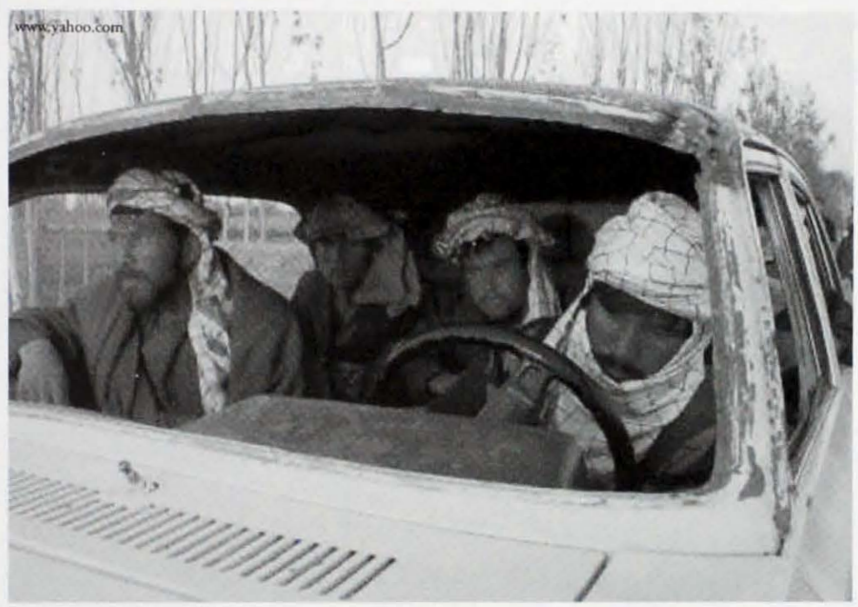

las autoridades piden que lo entreguen, pero ha sido en vano. Costa Rica, por su lado, igualmente ha buscado de forma infructuosa que entreguen a John Hull, un propietario de tierras en Costa Rica, que se le acusa de crimenes terroristas al estar utilizando la tierra como una base para la guerra de Estados Unidos contra Nicaragua en la década de los 80 .

Estados Unidos y Gran Bretaña apoyaron a Saddam Hussein, ahora enemigo de ambos gobiernos tras la Guerra del Golfo, durante sus peores atrocidades, incluyendo $\mathrm{el}$ asesinato con gas contra los kurdos. Si se considera a la coalición formada contra cl terrorismo, Rusia estaría de acuerdo en que Estados Unidos apoye su guerra terrorista contra Chechenia; China se deleitaría en recibir apoyo de Washington por las atrocidades que está comeriendo en China occidental contra los secesionistas musulmanes (unos ocho millones de personas que forman la minoria turca musulmana, los uigulsres en Xinjiang, región que comparte una frontera de 76 kilómetros con Afganistán), cuya región está repleta de minerales que son cruciales para el desarrollo económico de China.

Turquía se une a la coalición a pesar de ser considerado un gobierno masacrador de la población kurda que habita en el sudeste del pais, pero aún así recibe apoyo decidido de Washing. ton, ya que es el principal receptor de armas (tanques, aviones de combate F-16,

recursos en juego en la actual guerra, lo mismo que la del Golfo Pérsico, la misma proviene de un poderoso concurso geopolítico.

Ciertamente es ambigua la guerra lanzada por Estados Unidos contra el terrorismo internacional, sobre todo cuando se impone de manera unilateral la concepción del mismo sólo desde los intereses norteamericanos, olvidando, como lo registra la historia, las acciones contraterroristas emprendidas por Washington evocando la libertad y la democracia como valores supremos de Occidente.

Haiti ha estado solicitando a Washington que extradite a Emmanuel Constant, a quien acusa de responsabilidad por la matanza de 4 ó 5 mil personas a mediados de los años $90^{30}$. bajo una junta militar que estaba apoyada por Bush

entrenamiento militar, etc.) de Estados Unidos, sólo superado por Colombia. El primer ministro turco, Ecevit, anunció que contribuiria con tropas: "Tenemos una deuda de gratitud con Estados Unidos porque fue el único país que estuvo dispuesto a contribuir de manera tan masiva a nuestra propia guerra 'contra-terrorista' " ${ }^{31}$, lo cual no fue sino una limpieza étnica contra una población indefensa.

El peor violador de los derechos humanos en los años 90 fue Colombia, sin embargo fue el principal receptor de ayuda militar de Estados Unidos en 1999 para mantener el terror y las violaciones de derechos. Argelia, por otra parte, muestra estar de acuerdo con la guerra contra el terror que encabeza Washington, pero su gobierno es uno de los Estados terrorista más sanguinarios del mundo, al estar aplicando un terror contra su propia población durante los últimos años. El apoyo norteamericanos aląocupación militar israclí 
dura y brutal, ya lleva 35 años y relativamente sin visos de solución, a pesar de los acuerdos de Oslo.

El embajador israell en España proclamaba que en el terrorismo no habła que ver más que eso, terrorismo, cuyo paradigma serfa el palestino, soterrando la larga tradición de terrorismo político sionista, desde la voladura del Hotel Rey David en Jerusalén, en 1946, hasta el actual de Ariel Sharon; rambién el ex primer ministro Netanyahu reducía toda la lucha del bien, encarnado en el 'mundo libre', y el mal, personificado por Yaser Arafat y la OLP, un 'terrorismo internacional' que debe ser aplastado ${ }^{32}$. Por cierto, sobre el actual primer ministro de Israel, Ariel Sharon y el actual Ministro de Defensa, Amos Yaron, entre otros, existe un acusación ante un Juzgado de Instrucción en Bélgica, por la masacre, tortura, violaciones $y$ desaparecidos de entre mil y 3 mil 500 civiles - niños, mujeres y ancianos, en su mayor/a -, registrándose entre el 16 y 18 de septiembre de 1982 en los campamento de refugiados palestinos de Sabra y Chatila, situados en la periferia sur de Beirut ${ }^{33}$.

El gobierno estadounidense designó, tras los ataques del 11 de sepriembre, a su embajador ante Naciones Unidas, John Negroponte, quien tiene antecedentes de haber sabido de los asesinatos en gran escala y otras atrocidades que estaban siendo cometidos por las fuerzas de seguridad en Honduras ${ }^{34}$. siendo el embajador norteamericano en éste pals, lo cual constata mucho del apoyo norteamericano al gobierno hondureño - sobre todo a las fuerzas armadas- a principios del decenio de los 80 . Se sabe que el actual embajador de Naciones Unidas fue el supervisor local de la guerra terrorista conducida en Honduras, y probablemente por conocer su trabajo fue nombrado con ese cargo en dicho organismo internacional para conducir la guerra contra el terror.

Por otra parte, el odio que muestra Bin Laden hacia Estados Unidos no es en absoluto un capricho islámico o cuyas causas hay que encontrarlas en la vida norteamericana como epifenómeno paradigmático. En 1998, se agruparon Al Zawahri y Bin Laden, para constituir el denominado Frente Islamico Mundial para purgar contra los judios y cruzados, es decir, los infieles según su visión.

¿Por qué se opusieron a los Estados Unidos? En primer lugar por la invasión de Arabia Saudita por parte de Washington en 1990, estableciendo bases militares permanente en el Emirato árabe, y peor aún por lesionar el sitio más sagrado del Islam en la Peninsula árabe. Este es el morivo principal por el cual las actividades de Bin Laden y su organización Al Qaeda se volvieron contra Estados Unidos. Aunque muchas personas del mundo árabe y musulmán odian a Osama Bin Laden, lo siguen apoyando en muchos sentidos e incluso lo consideran como la conciencia del Islam, por su forma ortodoxa de interpretación ${ }^{35}$.

\section{Hegemonia de estados unidos: Geopolítica estratégica}

$\mathrm{N}$ o hay duda que tras el derrumbe del experimento socialista en Europa del Este a finales del decenio de los 80 , salió victorioso el sistema capitalista bajo la égida de la única superpotencia mundial: Estados Unidos de América. Su otrora contrapeso militar que amenazaba su hegemonia en tiempos de la guerra frla y aseguraba un equilibrio en el mundo. El Pacto de Varsovia, se disolvió paralelamente al derrumbe de la URSS y la caida estrepitosa de los reg!menes aliados a éste pals, al tiempo que se fortaleció la OTAN, símbolo de la distensión y contención de Occidente que se preserva ante la desaparición de aquél, actuado tras el colapso soviérico en varios escenarios de guerra: Kosovo, Yugoslavia y Croacia.

A ralz de los cambios internacionales propiciados desde la década de los noventa, la supremacla de Estados Unidos se ha hecho sentir a partir de los intereses geopoltricos de Washington en la nueva realidad emergente. Las áreas de influencias necesariamente entroncan con la hegemonfa y la seguridad norteamericana, propias de una potencia imperial que expande sus intereses por el mundo. El poderlo militar que sostiene esa hegemon/a hace uso de la sofisticada tecnología militar, dentro de una concepción de guerra toral muy diferente a los moldes tradicionales de guerras anteriores a la del Golfo Pérsico. Hoy Afganistán siente en suelo y carne propia ese poderío descomunal de un arsenal militar preparado por la industria militar norreamericana para destruir a paises enteros y aniquilar vidas humanas, principalmente de personas civiles (inocentes niños y madres) que se convierten en la víctimas de los "efectos colateralesw de los cientos de misiles "inteligentesw mortfferos. Una investigación realizada por el Congreso Federal de Estados Unidos demostró que las misiones de bombardeo de los aviones sofisticados B-2 alcanzaban una tasa de éxito de aproximadamente 40 por ciento, comprados con el 80 por ciento que sostenían los funcionarios durante la guerra del Golfo ${ }^{36}$.

A pesar de la terrible paranoia de guerra que ha embarcado Estados Unidos y Gran Bretańa contra Afganistán, los sucesos del 11 de sepriembre no sólo resquebrajaron el mito de la invulnerabilidad del territorio y seguridad norteamericana, sino que es sintomático de un poder hegemónico en declive que no ha entendido las realidades geopolíticas ${ }^{37}$. Ciertamente hoy, en el conflicto que se libra en Afganisrán, no se está definiendo la lucha por el poder a escala mundial entre los contendientes en el conocido terreno de la geopolitica como en el pasado, pero tampoco hay que descuidar y olvidar el forcejeo geopolítico entre China y Rusia ${ }^{38}$ según sus intereses en juego, sobre 
todo a partir de como evolucionen los hechos durante y después del conflicto en Af ganistán. Estados Unidos persiste en mantener su incontestable supremacia y hacer verdad el aforismo: mi voluntad es la ley. La guerra de Kosovo, el bombardeo a Irak y la negativa a aceptar los convenios de Kioto para reducir las emisiones contaminantes confirman ese aforismo.

Tal como lo demostró la guerra del Golfo de 1991 , los intereses vitales de Estados Unidos forman parte de su estrategia geopolitica en la región del Golfo de asegurar un recurso necesario que posee dicha zona: el petróleo. Jin Cason y David Brooks ${ }^{39}$ precisan que aproximadamente el $65 \%$ de las reservas petroleras conocidas del mundo están concentradas en Medio Oriente y Asia Central (incluyendo Afganistán), agregando que “...Desde el punto de vista energérico el significado de Afganistán emana de su posición geográfica como ruta de tránsito potencial para exportaciones de petróleo y gas natural de Asia central al Mar Arábigo", además de sostener que "Afganistán tiene sustantivas reservas de gas natural y algunos recursos de petróleo y carbón".

Sin embargo, a mediados del decenio de los noventa Washington aceptó políticamente al gobierno talibán como resultado de la influencia que tiene la empresa petrolera estadounidense UNOCOL -compañía con sede en Houston, Texas, cercana a los actuales presidente y vicepresidente, Bush y Cheney-principal inversionista en un consorcio internaciona] que negoció y finalmente acordó un contrato de dos mil millones de dólares con el gobierno talibán para construir un oleoducto de 890 millas de largo, que atravesaba Afganistán para transportar gas natural de Turkmenistán a Pakistán, proyecto que tuvo problemas políticos en 1998 debido a las políticas sociales del régimen talibán, precisamente en derechos humanos y derechos de la mujer.

En ese mismo año, la compañía invitó al talibán a Estados Unidos, paseándolos por la compañía y al mismo riempo proponiéndoles transportar crudo del Mar Caspio a los puertos de Pakistán vía Afganistán, es decir, sin pasar por Rusia o Irán ${ }^{40}$, aunque en la prácrica el acuerdofiue bloqueado por las fuertes objeciones realizadas por las feministas $y$ ambientalistas. Este hecho permite pensar que si el régimen talibán es derrocado, Estados Unidos podría reabrir este acuerdo de un oleoducto que generaría miles de millones de dólares entre UNOCOL y un probable gobierno de coalición proestadounidense.

La supremacía de Estados Unidos es celosamente resguardada por el stablishment gobernante, cuya experiencia bélica no es de menor dato. La integración del gobierno de George W. Bush hijo tiene connotados exponentes y alentadores de guerra, tanto ayer como hoy, entre ellos su vicepresidente Richard Cheney, quien fuera secretario de Defensa de Bush padre durante la invasión a Panamá en 1989 y la guerra del Golfo en 1991 contra Irak y Saddan Husseim; el actual secretario de Estado, general Colin Powel, fue jefe de Estado Mayor del ejército durante la guerra del Golfo; el actual secretario de Defensa, Donald Rumsfeld, desempeñó el mismo cargo durante la presidencia de Gerald Ford entre 1973 y 1977. No son ningunos improvisados al menos quienes dirigen la guerra, son los halcones de la guerra, excepto el presidente que es un empresario texano vinculado al petróleo, pero eso no lo sustrae de ser partidario de los experimentos de guerra.

El stablishment norteamericano, cuyo poder hegemónico es indiscurible, no necesita del Consejo de Seguridad de Naciones Unidas para arremeter su guerra contra Afganistán, violando la carta de constitución de ese organismo y convirtiéndolo en un espectador pasivo que contradice su verdadera función en asuntos internacionales.

Existe un error de apreciación objetiva acerca de la compresión del atentado terrorista en ciertos círculos intelectuales de Estados Unidos: «La raíz de los atentados se halla en la interacción de dos factores de orden político: la hegemonía de los Estados Unidos y el estancamiento del mundo islámico en los últimos siglosn ${ }^{41}$, valoración por cierta ramplona y subjetiva en su sostenimiento. Igual agravio a! pensamiento resulta esgrimir que "el mundo musulmán experimentó y continúa experimentando la emergencia de Europa y la actual hegemonla militar Nortcamérica como

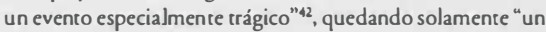
resentimiento radical contra el Norte".

No resulta plausible sostener que el idinamismo de EE.UU, lo convierta en el espejo en el que se miran las demás 
naciones", peor aún que sea "depositaria del proyecto que nació... en el vicjo Continenten, como lo afirma el autor. No estamos seguros que el American way of life tenga que ser el patrón universal plausible fuera del mundo Occidental, desconociendo culturas y tradiciones arraigadas entre los pucblos no occidentales por más atrasados que sean; antes bien, puede ser un referente pero nunca un mimerismo.

La guerra que se está librando contra Afganistán desde el 7 de occubre del 2001, igual que la mayoría de las guerras que le precedicron, tiene su rafz en la comperencia geopolítica. Aunque el conflicto se desarrolla en tierras afganas, el verdadero foco $c$ interés está pucsto en Arabia Saudita ${ }^{43}$, no en Afganistán, ya que una de las demandas de lucha de Bin Laden consiste en la imposición de un nuevo gobierno en el reino que controlaría el más importante botín geopolítico sobre la faz de la tierra: las vastos yacimientos perroleros sauditas, que representan la cuarta parte de las reservas de petróleo conocidas en el mundo. Este es el verdadero interés de W/ashington en su operación Libertad Duradera, al precio de castigar al pucblo afgano con más miscria y atraso.

Desde los tiempos de la definición y término de la segunda guerra mundial, el “Departamento de Estado recibió el encargo del presidente Roosevelt de implementar políticas c instituciones que garantizaran la seguridad y la prosperidad de Estados Unidos para épocas venideras. Esto incluyó el discño y la creación de la Organización de Naciones Unidas, la construcción de las instituciones financieras de Bretton Woods, y aún más significativo en el actual contexto, la procuración de un suministro adecuado de petrólcon ${ }^{44}$.

Desde esta perspectiva, los estrategas norteamericanos previcron que el acceso al petróleo era especialmence importante dado que esto haría un factor esencial en la victoria de los aliados. En esos tiempos fue el petrólco el que movilizó a canques, buques $y$ aviones que permicieron a las fuerzas estadounidenses la ventaja decisiva sobre sus adversarios, quienes carecian precisamente de fuences confiables de combustibles. De ahí que era lógico dar por hecho que el acceso a un abundante suministro de petróleo sería crítico para el éxito de Washington en futuros conflictos. Para enconces el asesor económico del Departamento de Estado, Herbert Feis, luego de estudios intensivos realizados, concluyó gue sólo un lugar podía provecr del petróleo necesario: Medio Oriente y de manera particular la reserva petrolera sin explotar más prolífica del mundo en el reino de Arabia Saudita"s

En este sentido, pasaron a un segundo plano México y Venezucla como suministradores del crudo para Estados Unidos. Para concretar los planes se creó una alianza entre las corporaciones petroleras estadounidenses y la Compañia Arabe Americano de Petróleo (ARAMCO, por sus siglas en inglés), lo cual implicaba una unión entre el presidente Roosevelt y el rey Abd al Aziz lbn Saud, fundador del reino moderno saudita, hecho extraordinario en la historia moderna norteamericana que significó que el presidente norteamericano le prometió protección de Estados Unidos a cambio de acceso privilegiado al perrólco saudita. Los beneficios de esta jugosa negociación perduran hasta hoy, a favor de ARAMCO y sus socio estadounidenses. Este es el núcleo esencial de la relación estadounidense-saudita.

Michael T. Klare lo ataja coloquialmente: "Arabia Saudita también compra anualmente entre 6 mil y $10 \mathrm{mil}$ millones de dólares de producros de empresas estadounidenses. De su parte, la f:amilia real saudita se ha vuclto inmensamente rica debido a que la protección estadounidense le ha permitido mantenerse a salvo de agresiones internas y externas $n^{46}$.

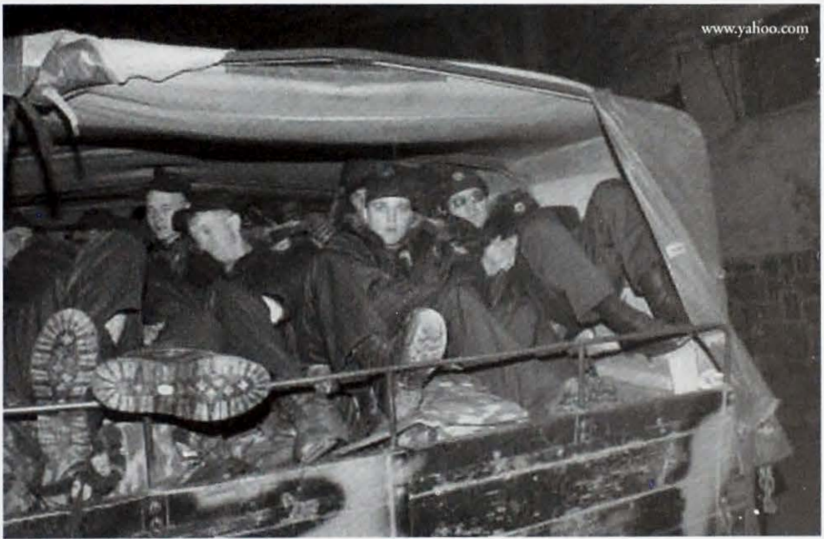

La consecuencia de esta alianza es que para proteger al reino saudita de sus enemigos externos. Estados Unidus ha expandido sostenidamente su presencia militar en la región, al desplegar miles de tropas en el reino, a tal grado que personal norteamericano se ha involucrado en el aparate de seguridad interna del régimen, mientras internamente son declarados ilegales las formas de debate político en el reino y, además, han utilizado a liss fuerzas de seguridad entrenada: 


\section{Análisis político de la guerra angloamericana contra afganistán}

por Estados Unidos para aplastar cualquier expresión de disidencia (no hay P'arlamento, ni libertad de expresión, no hay partidos políticos ni derecho de asamblea, no hay conscitución, etc). Así, Estados Unidos protege y defiende a una paradigmática autocracia dentro del mundo árabe. aunque no es el ínico tampoco. Todo esto ha traido graves consecuencias al reino con actos de violencia y, por su puesto, de parte del saudí Osama Bin Laden.

Ya lo advirtió el destacado historiador Eric J. Hobsbawn, "...la superpotencia americana, la única potencia del planeta, no está en condiciones de controlar y gobernar el mundon ${ }^{47}$; más contundente es el planteamiento de Immanuel Wallerstein al hacer un balance de los úlcimos ańos: "Washington podria lamentar el dia que Assad, Kadafi, Arafat c incluso Saddan Husscim ya no estén el poder...sus sucesores podrian ser anciestadounidenses más feroces porque a diferencia de esos personajes, ya no compartirán valores modernistas con Estados Unidos... Consideren que esto bien pudo ser el Plan de Bin Laden. Su propia misión suicida pudo haber tenido el objecivo de llevar a Estados Unidos hacia esa trampa"48

\section{Afganistán y el mundo islámico}

T a cultura árabe y musulmana es sui generis en todo su Lordenamiento y forma de expresión particular, que no puede dirimirse en el dilema 7he Clash of civilizanions como lo predijo el ideólogo de Harvard Samucl Huntington en 1993 tras el derrumbe de la Unión Soviética. Ese ensayo, en honor de rescatar la cultura árabe y musulmana, ha sido desautorizado por el intelectual palestino y académico de la Universidad de Columbia, Edward W. Said, con el título "El choque de las igsorancins,". No se trata, en efecto, de encasillar el problema en maniqueísmo y epitecos del tipo Islam contra Occidente, porque ello oscurece el pensamiento y debilita la reflexión justa del entendimiento humano. Uno de los efectos perversos de los atentados del 11 de sepriembre es la satanización de todo lo que hucle a árabe y a Islam. despertando un tipo de racismo entre muchos occidentales para saldar cuentas con ese referente cultural.

La lucha encarnizada entre grupos del mundo musulmán islámico y sus enemigos occidentales o prooccidentales, tienen una raiz politico-ideológica de agresión y hostilidad permanente contra los intereses islámicos, por un lado, y por la traición de los principios del Corán de parte de ciertos gobernantes musulmanes aliados a Estados Unidos.

No existe unidad, en efecto, en el mundo árabe $y$ musulmán. Pakistán. Egipto y Arabia Saudita se han alincado con Washington en la guerra contra Afganistán. Irán es acérrimo enemigo de los calibanes, a cal grado que ha dado cicrto apoyo a la Alianza del Norte que combate el régimen de Kabul, peroha mostrado opuesto a la guerra y ha suplicado que el conflictu se dirima en el seno de Naciones Unidas. Pero eso no implica que no haya tenido resonancia en el mundo islámico musulmán y árabe los mensajes de Bin Laden para defender al Islam y atacar al enemigo infiel, Estados Unidos y sus aliados.

Hoy está en el ojo del huracán el mundo islámico musulmán como portador del terrorismo internacional, por haber perpetrado un grupo de personas de ese mundo al estilo kamikases un acto de barbaric en territorio estadounidense el 11 de septiembre, cobrando la vida de más de cinco mil personas. Este atentado es la culminación y continuidad de una seric de hechos violentos que grupos radicales islamitas musulmanes han perpetrado de diferentes partes del mundo, con la diferencia fundamental que hoy fue una profunda herida en el corazón de la superpotencia mundial, en su propio territorio y ante la los ojos de sus propios ciudadanos.

Los antecedentes demuestran que el islamismo nació en el valle del Nilo (Egipto), a través de la predicación de hace 70 ańos de Hassan el Banna, macstro de la escuela y

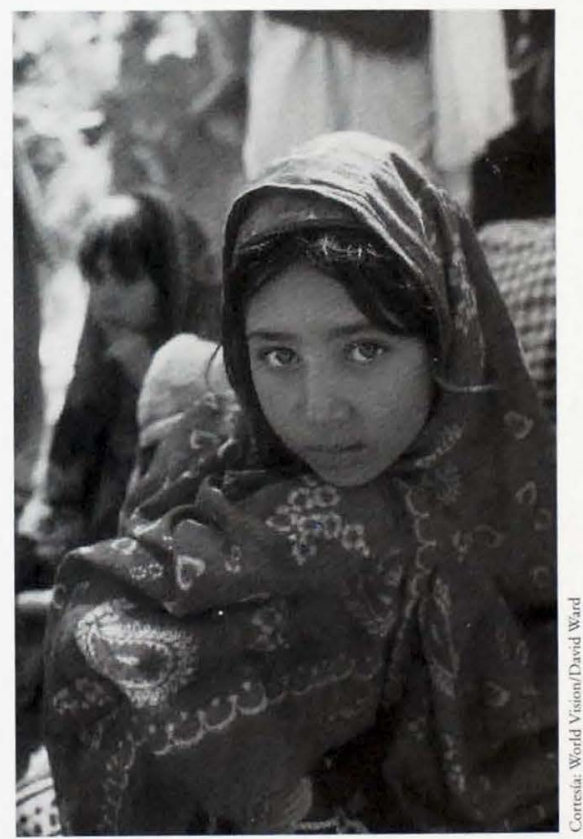

Diciembre 2001-Enero 2002, №. 22 
fundador de los Hermanos Musulmanes ${ }^{50}$, el segundo gran poder en el valle del Nilo tras el régimen de Mubarak - quien lleva 20 años como rais - y con presencia en 70 países bajo distintas denominaciones que pueden o no ser la de Hermanos Musulmanes, cuyo mayoritario Islam sunles se conscituye en la mayor fuerza del que podría llamarse integrismo moderado, siendo aún más viejo que los integrismo radicales $y$ hasta terroristas.

Actualmente, sobre todo a partir de la década de los noventa, existe una forma de reislamización que tiene como trasfondo no sólo la derrota del Egipro de Nasser en la guerra de los Seis Días en 1967 a manos de israelies y sus protectores norteamericanos, sino también por la apostasía cometida por gobiernos (Arabia Saudita, Egipro, etc.) que abandonaron el Islam y llegaron a ser corruptos, además de permitir la ocupación de extranjeros en territorios musulmanes. A raíz de esta situación el concepto dominante no es precisamente el arabismo, sino el de la umma islámica, esto es, la comunidad de creyentes, sean árabes, afganos, paquistanies, saudís, indonesios, filipinos, etc.

La sentencia de Maamun el Hodeibi, portavoz de los Hermanos Musulmanes, no da lugar a dudas: «EE.UU. pagará su ciega agresión contra un país islámico [Afganistán]" ${ }^{51}$. Desde el asesinato de Sadat en 1981 por miembros del grupo egipcio Al Yihad - cuyo lider es el cirujano Ayman al Zawahri, lugarteniente de Osama Bin Laden-Mubarak tiene encarcelados a 16 mil islamitas, que de seguro hubieran servido en el momento actual a una revuelta islamita contra su gobierno que hoy sirve de aliado a los intereses de Estados Unidos para bombardear a Afganistán.

El la segunda mitad de los años noventa, Al Zawahri y Bin Laden, llegaron a la conclusión de que la reconquista islámica de Jerusalén, la caída de los regímenes prooccidentales de El Cairo y el Riad"(Arabia Saudí) y la salida de las tropas norteamericanas de la sagrada tierra de éste país pasa por Washington. En esta línea de pensamiento estratégico y bajo la protección de los talibanes afganos que llegaron al poder en 1996, formaron con egipcios de Al Zawahri, saudis y yemíes de Osama Bin Laden y sus aliados sudaneses, paquistaníes, bangladeshíes y africanos las primeras brigadas internacionales de la jihad of ensiva aglutinadas en la organización Al Qaeda (la base).

En el término jihad - guerra indiscriminada contra los supuestos enemigos- es improbable reconocer la religión, la sociedad, la cultura o la política islámicas como las han vivido y experimentado por siglos los musulmanes ${ }^{32}$. Para los musulmanes Islam satisface y culmina la línea de una profecía. De hecho, si se acepta que el Islam actúa en el mundo musulmán como vehículo natural de la política, el Corán sirve de fuente de justicia, humanidad, buen gobierno y oposición a la corrupción. Estas podrían ser algunas razones de Bin Laden de apertrecharse en el Islam y lanzar su jihad contra Estados Unidos y sus aliados, incluyendo a los del mundo arabemusulmán.

La jihad recibe en la azora IV del Corán formulaciones inequivocas en el sentido que no existen límites en el combare por destruir a los enemigos del Islam: "Quienes creen, combaten en la senda de Dios, "combatid a los amigos del Demonio, 'a quienes combaten en la senda de Dios, sean matados, sean vencedores, les daremos una enorme recompensa. 'Un difa de defensa del Islam vale más que todo el Mundo y todo lo que hay en él ${ }^{53}$, reza un hadith. Esa convergencia de lucha implacable por la creencia y recursos taimados y sanguinarios cuajó en corno al año mil 100 en el principal antecedente de lo que hoy sucede: la ejecución por el ismaili Hasan-i Sabbah, desde su castillo de Alamut, de una estrategia de eliminación de todo adversario religioso o político a cargo de auténticos comandos suicidas de sus leales, los 'asesinos's4.

Es necesario recordar que Osama Bin Laden es un wuahhabita, la vertiente islámica que es religión de Estado en la Arabia Saudí, para la cual toda la verdad se encuentra en el Corán y en los hadiths, dichos atribuidos a Mahomass. El peot error sería hacer de Bin Laden el protocipo del musulmán. Con la occidentalización de la dinastía, los mohabitas ortodoxos la consideraron traidora, teniendo lugar en 1979 una insurrección xenófoba en La Meca que terminó con la muerte de 450 rebeldes y dos mil 700 soldados. En ese sentido, no resulta extraño en esa coyuntura finisecular que designar a Estados Unidos cabeza del mundo occidental, como el gran Satán que entraña la negación en todos los 


\section{Análisis político de la guerra angloamericana contra afganistán}

ámbicos d la ortodoxia coránica y de la hegemonía politica del Islam. Por eso mismo, la guerra del Golfo, el triunfo de los talibanes ortodoxos en Afganistán y el dominio cjercido por Israel en P'alestina, son referentes precisos que incitan a la respuesta violenta en nombre de Alá.

El disidente del reino saudi, Osama Bin l.aden, se ha declarado enemigo del régimen saudita, por haber permitido y ensuciado la tierra santa del reino con la presencia norteamericana en la Península Arábica; sin embargo, la protección del reino de parte de Estados Unidos es su mayor problema. De hecho, el involucramiento militar estadounidense en el reino alcanzó niveles altos en 1979 a partir de dos hechos importantes en la región: la invasión de La URSS en Afganistán y el siba de Irán fue derrocado por fucrzas opositoras y militantes islámicos que protagonizaron una breve revuetta en La Meca. En este último hecho que marcó un viraje drásticos en la política irani, el entonces presidente norteamericano, el demócrata Jimmy Carter, lanzó su política en los siguientes términos: cualquier tentativa de un poder hostil encaminada a lograr el control sobre el Golfo Pérsico scrá considerado "un ataque sobre los intereses de los Estados Unidos de Américan, y serii repelido "por todos los medios necesarios, incluida la acción militarn".

Ésta ha sido la tónica de la estrategia norteamericana en la zona y que perdura hasta hoy. Frente a una amenaza mayor, Carter desplegó buques de guerra en el Golfo y arregló que las fuerzas estadounidenses pudieran hacer uso periódicamente de bases militares en Bahrein, en Diego Garcia (una isla bajo control británico en el ocćano Indico). asicomo en Omán y Arabia Saudita. Todas estas bases fucron empleadas entre (9) 0 y 1 (9) 1 durante la guerra del Golfo, $y$ se cstán usando en el conflicto de hoy contra Afganistán.

Ronald Reagan, en la década de los ochenta, intensificó los abiertos movimiento militares en la zona $\mathrm{c}$ incrementó $\mathrm{el}$ apoyo oculto a los mujaidines antisovićicos en Afganistán, con un costo estimado en armas de unos 3 mil millones de dólares ${ }^{57}$. Después siguió Bush padre con su guerra del Golfo c igualmente Clinton prosiguió con h misma política; éste último buscó extender las influencias de su pais en el valle del mar Caspio, un área rica en energéticos al norte del Golfo Pérsico. Muchas cosas han ocurrido después. Las sanciones contra Irak han causado desde la guerra del Golfo inmenso sufrimiento en el pueblo iraki, estimaciones de Unicef confirman que las muerés de niños rondan por los 500 mil anual por la falta de medicinas $y$ alimentos causados por $\mathrm{el}$ embargo.

Ciertamente cuando los talibanes llegaron al poder tras derrocar al gohierno moderado islamita de la Alianza del Norte, Afganistán heredó un país plagado de campamentos de inserucción para activistas y radicales islámicos procedentes de coda Asia, los cuales fueron vitales para infligir una derrota a los sovicticos en 1989. Se afirma que los chechenos, los oighures, los cachemires, los uzbecos, erc., han estado utilizando Afganistán para adiestrarse en guerra de guerrillas ${ }^{5 R}$, muchos desde hace 20 años.

"Estrictamente hablando, no es Afganistan el que ha gencrado los movimientos, sino más precisamente, han sido

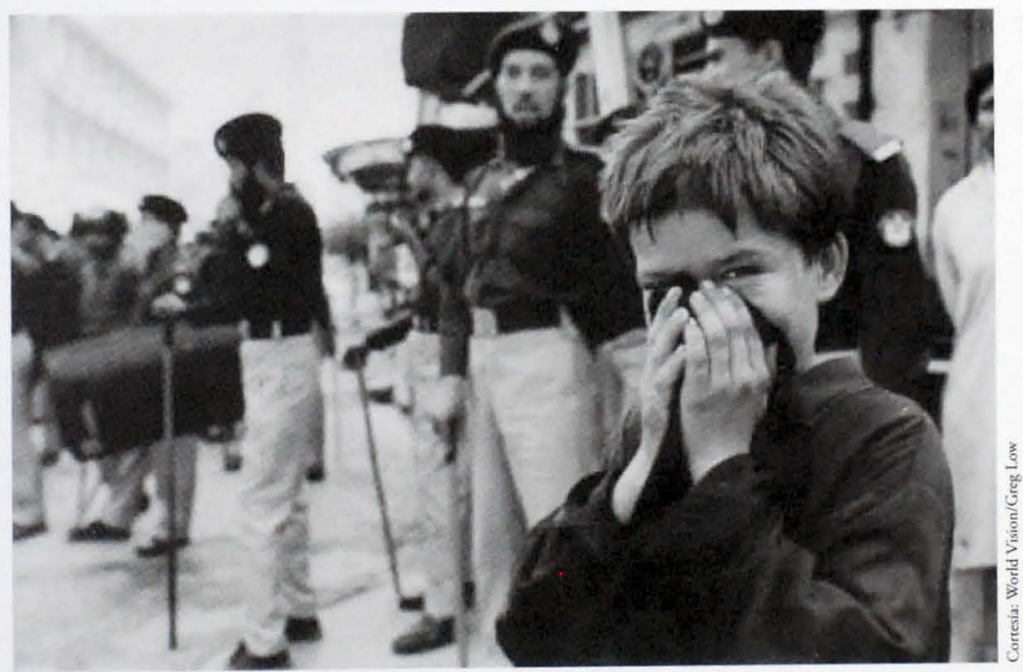


las condiciones generales las que han generado los movimientos que han buscado refugio en Afganistán "s9. Es por esta razón que muchas potencias regionales de la zona India, Irán, Rusia, China, incluso Uzbekistán- estarían complacidos del derrumbe del régimen talibán que proporciona refugio a sus movimientos de oposición; sin embargo, en este punto Washington tendría que enfrentar a compañeros difíciles de digerir. La mayoría de ellos son hostiles a cualquier asomo de hegemonía de Estados Unidos en Asia y al unilateralismo de Washington, pues temen a una respuesta militar estadounidense en la puerta de su casa, fortaleciendo el intervencionismo estadounidense en todo el mundo.

En esa maraña geopolítica que acontece en Asia Central, Pakistán está ante una posición difícil y delicada pues no sólo ayudó a los calibanes a acceder al poder en ese país para restaurar el orden, además los talibanes son un aliado útil, sino que si entregara a Osama Bin Laden enfrentarfa una reacción y oposición islámica que lo considera un héroe por haber luchado con éxito no sólo contra la URSS sino contra el imperialismo estadounidense. Desde esta perspectiva, serı́a hasta irónico que en sus ansias de venganza Estados Unidos capturara a Bin Laden y en el camino perdiera a Pakistán a favor de los fundamentalistas partidarias de línea dura.

Se sabe que Bin Laden ha concentrado sus esfuerzos en alcanzar dos objerivos colosales: expulsar a los "infielesn estadounidense de su país Arabia Saudita (el corazón de la tierra santa musulmana) y derrocar al actual régimen saudita para sustituirlo por otro más coherente con sus creencias fundamentalistas islámicas, los cuales ponen al saudí en conflicto directo con Estados Unidos. Un desafio nada fácil ante la protección norteamericana del reino. Sin embargo, la partida decisiva se juega en el interior del mundo musulmán, donde sobran recursos políticos y religiosos para contrarrestar la explosión integrista que se ha desatado.

Resulta contraproducente para Washington que Bin Laden controle un gobierno saudita porque ello sería destruir todos los nexos con las compañías petroleras estadounidenses y adoptaría nuevas políticas en cuanto a la producción y distribución del petróleo del país, medidas que traerían potencialmente devastadoras consecuencias para Estados Unidos, y desde luego, para la economía mundial; sin embargo, Washington está luchando para evitar ese escenario contrario a sus intereses vitales en el Golfo.

Desde entonces, Al Qaeda ha infligido ataques a intereses norteamericanos dispersos por el mundo. Los ataques a la embajada norteamericana en Sudán y el kamicaze contra el navío Cole de la armada de Estados Unidos, han llevado su impronta bélica ofensiva. El ataque del 11 de septiembre es la culminación, hasta hoy, del accionar continuo de los grupos que se oponen a la política norteamericana de promover, apoyar y financiar la violencia contra el mundo árabe musulmán. La estrategia de seguridad de Washington resultó fallida ante un ataque inesperado que puso en cuestión su viejo esquema de seguridad heredado de los tiempo de la guerra fría. Susan Sontag lo describe en forma escueta: "...nuestros protectores han sido incréblemente inepros" ${ }^{60}$, lo cual se revierte sobre la FBI, institución que tenfa bajo vigilancia a uno de los sospechosos del aerosecuestro, Mohammad Atta, y que misteriosamente apareció entre los kamikazes que se estrelló contra una de las torres gemelas de Manhattan.

Ahora bien, la organización Al Qaeda es un conglomerado de grupos dispersos por codo el mundo que operan como una red. Sus afiliados incluyen, entre otros, a Yihad Islámica Egipcia (EIJ), Al Gammaya al Islamia (IG, grupo islámico de Egipto), Grupo Armado Islámico de Argelia (GlA), Partido Islámico de Turkestás (IPT), Movimiento Islámico de Uzbekistán, Jayashee Mahoma de Cachemira (JM), Ejército de Mahoma y Grupo Abu Sayyaf (ASG) de Filipinas ${ }^{61}$. Los grupos que constituyen AJ Qaeda tienen su propia mando, control y estructuras de comunicación; pero para cualquier necesidad, esos grupos se interrelacionan o se unen, ideológica, financiera y operativamente. Al Qaeda otorga liderazgo, tanto nacional como internacionalmente. Aboga por panislamismo dentro de su programa ideológico, por tanto, Osama Bin Laden acaba con la divisiones y apela tanco a los grupos de Oriente Medio como a los que no son de esa región, incluyendo a los grupos islámicos de Asia. Su pensamiento en esta dirección recibió una gran influencia tanto de Abdullah Azzam, su mentor palestino, como de Hasan Turabi, el líder espiritual de Sudán. Se afirma que Al Qaeda tiene un alcance global, ya que dirige infraestructuras de apoyo en Oriente Medio, Asia, Europa y Norteamérica ${ }^{62}$.

La red A Q Qaeda de apoyo a la células está comprometida en la propaganda, la recaudación de fondos, el reclutamiento de miembros y ayudantes, la formación de grupos de espionaje, la consecución de misiles y tecnología duales, la organización de entrenamiento, la preparación de viviendas seguras, la consecución de vehículos y la falsificación/ adaptación de identificaciones. $\mathrm{Al}$ mismo tiempo que dirige inf raestructuras permanentes de operaciones en zønas de Asia (central, sur y sudoeste), los Balcanes, el Cáucaso, Oriente Medio y el África subsahariana, tiene una capacidad de establecer también la regeneración de células operacionales en cualquier parte, especialmente en Occidente. Esas células. educan, organizan reconocimiento/vigilancia $y$, por su puesto, dirigen ataques.

Las fuerzas de Al Qaeda están integradas en los talibán y se beneficia materialmente de la protección del Estado ${ }^{63}$. Los estrategas de combate de Al Qaeda, lo expertos en explosivos y otros especialistas actúan como educadores y

Diciembre 2001-Enero 2002, entorno

entorno

entorno

entorino

sintorno

entorno

enlorine

entorino

Gilkering

entionito

entorino

entorno entorno eiviorino entaring entorino entorino entorino entorino Bilorino siflorito Aniverno entorno entorno entorno sntorno entorno Grilonte entorna entorno entorno enterna entorino entorno entionins entorita

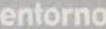
antoring Bing antorise entorina entoras Antortio entorino sintoring entorino entorino entorino entorno Entoribo Entorno 
consejeros, al tiempo que participan activamente en campañas de 'yihad' desde Chechenia hasta Cachemira y Mindanao. La interacción de Al Qaeda con los talibán, la guerrilla y los grupos terroristas compromecidos en la lucha de primera linea, ha enriquecido su entendimiento $y$ experiencia de un amplio espectro de la guerra.

El aspecto más atractivo de $\mathrm{Al}$ Qaeda es su integración vercical y horizontal. Verticalmente, el corazón y el penúltimo Iíder lo forma Osama Bin Laden, otro grupo de líderes, sus consejeros, los planificadores y educadores. Horizontalmente, el tendido de la red en células compartimentadas se aplica cada dia. La mayor parte de las fuerzas de Al Qaeda denominada VSS brigada de los talibán- lucha contra la Alianza de Norte en Afganistán. Durante la última década, Al Qaeda ha crecido en fuerza y se ha situado entre los $4 \mathrm{mil}$ y 5 mil hombres; la base y los campos de entrenamiento están en Khost, Maharvia, Kabul, Jalalabad, Kunhar y Kandahar ${ }^{\mathrm{A}}$.
No se puede asociar arbitrariamente Islam y terrorismo por el actuar de un grupo islámico radicalizado que provoca terror con sus acciones suicidas. Es necesario entender las causas asumidas por esos grupos luego de la maduración de sucesos que han humillado a! mundo árabe y musulmán.

\section{En la operación}

Libertad Duradera de

Washington y Gran Bretaña, la probable lista de grupos y gobiernos terroristas a los cuales se les se ha declarado la guerra total en la sed de venganza de Washington, están:

\section{Grupo Al Qaeda}

Al Yihad, grupo islámico de Egipto dirigido por el cirujano AL Zawahri- dicho grupo asesinó, en 1981, al presidente Anuar el Sadar. El líder de este grupo está entre los 22 personajes terroristas más buscados por la $\mathrm{ClA}$.

Grupo Abu Sayyaf, en Filipinas, Laskar Jihad, en Indonesia Movimiento Islámico de Uzbekistán, Hezbollah en Líbano Hamas de Palestina, Jihad Islámica en Egipto, Gobierno de Irak, Gobierno de Sudán y Libia.

Quizá habría que darle la razón al intelectual de origen paquistani, Eqbal Ahmad, en el sentido de que *históricamente la experiencia de la violencia ejercida por el oponente fuerte[Estados Unidos] ha hecho de las víctimas terroristas" ${ }^{65}$, subrayando que el terror estatal muchas veces cultiva el terror colectivo.
Hay quienes empiezan a mostrar dudas sobre el apoyo de Estados Unidos a la Alianza del Norte que lucha contra el régimen calibán y que recibe apoyo de Washington y Rusia, pues ello significaría caer en la trampa de "el enemigo de mi amigo es mi amigon ${ }^{66}$ que dio lugar precisamence a la Watch ${ }^{67}$ indica que la Alianza del Norte acumuló una cantidad de horribles ataques a civiles cuando gobernó entre 1992 y 1996.

En la expedición punitiva contra Bin Laden el gobierno estadounidense podría quedar preso de su propia trampa, si las cosas se complican dentro de la coalición, principalmente muestras de simpatía con los talibanes en el mundo musulmán, tras los ataques de Estados Unidos contra Afganistán ${ }^{68}$, han sido sintomático en varios países, principalmente en su vecino Pakistán. emergencia de los talibanes. Un reporte de Human Rights de los paises árabes y musulmanes que hoy lo apoyan. Las

A más de un mes de intensos bombardeos sobre Afganistán, con saldos de centenares de personas civiles muertas a causa del indiscriminado ataque a las principales ciudades de ese pais, los desafíos políticos que enfrentará el gobierno futuro no son de poca monta, sobre todo considerando las pugnas entre etnias dif erentes, $y$ principalmente el hecho de que salgan derrocado los talibanes con la ayuda de los norteamericanos. El futuro de Afganistán es incierto, pero lo seguro que tendrá será la inestabilidad como hecho estigmatizante.

Bibliografía básica

Ali, Tariq̨, •Rebelión internacionala, La Jomada. Opinión, Mexico. miércoles 3 de occubre de 2001.

Borja, Rodrigo, "Enciclopadia de La politicat", FCE, 2* impresión, 1999.

Fisk. Robert. "Biografia de un rerıorisea (Osama Bin Laden, Lder integrista istámico)". El Pals. Personajes, 16 de sepciembre de 2001

Heribero Cairo Carou, "Geopolitrica cririca", Universidad Complutense de Madrid.

Documento Santa Fe IV'. I'criódico Desde Abajo. Colombia, 2000. 